\title{
EL PRINCIPIO DE IGNORANCIA Y EL PROBLEMA DE LOS PAGOS EN EL DERECHO PENAL
}

Diego Rengifo Lozano*

Fecha de Recibido: 28 de marzo de 2012

Fecha de Aprobación: 20 de junio de 2012

Artículo de Reflexión

Forma de citación: Rengifo, D. (2012). El principio de ignorancia y el problema de los pagos en el Derecho Penal. Revista Prolegómenos. Derechos y Valores, 15, 30, 45-64.

\begin{abstract}
Resumen
En tanto que el principio de ignorancia del derecho no prescribe una conducta determinada ni propone una sanción específica, sino que determina cierta restricción a los recursos de defensa, toda evaluación que se pretenda sobre él presenta cierta dificultad si de forma simultánea no se evalúa tanto la prescripción de la ley (su objetivo específico) como la proporcionalidad con que castiga su transgresión. Es precisamente ante esta consideración que los argumentos utilizados tradicionalmente para defender y refutar el principio de ignorancia del derecho se muestran insuficientes frente a la complejidad del problema.
\end{abstract}

\section{Palabras clave}

Predictibilidad, simpatía, pagos, sistema, eximentes, moral, delito y castigo.

\section{THE PRINCIPLE OF IGNORANCE AND THE PAYMENT PROBLEM IN PENAL LAW}

\begin{abstract}
Whereas the Principle of Ignorance of the Law does not prescribe certain conduct nor proposes a specific sanction instead determining certain restrictions of the defense resources, all evaluations about it will have certain trouble if they do not evaluate simultaneously both the prescription of the Law (its specific objective) and its punishment proportionality of transgressions. Precisely in view of this consideration, the traditionally arguments used to defend and to refute the Principle of Ignorance of the Law are insufficient due to the complexity of the problem.
\end{abstract}

\section{Key Words}

Predictability, sympathy, payments, system, defenses, moral, crime and punishment.

* Economista y Especialista en Derecho Económico de la Universidad Nacional, Magíster en Derecho Universidad de los Andes, Doctorado (c) en Sociología Jurídica e Instituciones Políticas Universidad Externado de Colombia. Profesor de posgrados Facultad de Derecho Universidad Nacional de Colombia. Correo electrónico: drengifol@hotmail.com 


\title{
O PRINCÍPIO DA IGNORÂNCIA E O PROBLEMA DE PAGAMENTOS EM DIREITO PENAL
}

\begin{abstract}
Resumo
Embora o princípio da ignorância da lei não prescreve um determinado comportamento ou propor uma penalidade específica, mas determina algumas restrições sobre os recursos de defesa, qualquer avaliação que se destina a que apresenta alguma dificuldade, se não simultaneamente avalia tanto prescrição do direito (objectivo específico) como lá proporcionalidade em punir sua transgressão. É precisamente esta consideração aos argumentos usados tradicionalmente para defender e refutar o princípio da ignorância da lei é insuficiente dada a complexidade do problema.
\end{abstract}

\section{Palavras-chaves}

Previsibilidade, simpatia, sistema de pagamento, defesas, moral, crime e punição.

\section{INTRODUCCIÓN}

Las implicaciones del principio ignorantia legis neminem excusat suelen ser percibidas empíricamente. De una parte, en el hecho cierto de que la sociedad en su gran mayoría funciona sin el conocimiento expreso de la ley y, de otra, el principio de ignorancia como problema de justicia, toda vez que en muchas ocasiones suele resultar injusto que quien ciertamente desconoce la ley padezca las consecuencias de la sanción como si la conociera, acorde al forzamiento que establece el modelo jurídico contando con la ficción como parte de sus presupuestos informacionales.

Se advierte así la valoración ética (injusta) y la imposibilidad de su cumplimiento (ficticia), y se resuelve recurriendo a la instancia jurís et de jure como ordenamiento que no tiene necesidad de legitimación en términos de una racionalidad que lo produzca, sino de un requerimiento que el derecho llama para su soporte y cuya justificación termina en el argumento circular de una exigencia del derecho sin la cual el sistema colapsaría. No deja de resultar paradójica la posibilidad de fallos divididos en las altas cortes, asumiendo éstas para los propósitos del análisis, como un bloque informacional no sólo por los efectos concretos de la jurisprudencia y la relevancia del precedente sino por la solidez técnica que se atribuye a sus miembros. Hemos de convenir en que los juristas que alcanzan dichas magistraturas han de tener a su haber un acervo de conocimiento jurídico apreciable. Luego, si gran cantidad de sentencias producidas en esa órbita rectora se fallan en presencia de controversias y salvamentos de voto ¿cómo esperar que el individuo común juzgue o "elija" de conformidad? ¿Con qué herramientas de juicio dirime el lego sus casos difíciles?

Estimando la información como insumo del conocimiento, el individuo no tiene que "conocer" la ley, en tanto no se le exige que sea capaz de explicarla sino que, en términos del principio de ignorancia, se le exige actuar como si estuviera informado, particularmente en el evento de que pretenda amparar la responsabilidad derivada de una conducta punible en ese desconocimiento. Esta exigencia alude primordialmente a un principio de responsabilidad, más allá del reconocimiento de la pena como condicionante de la conducta. El argumento procede y se deduce del hecho de que nadie conoce la ley en su totalidad, y mucho menos la sanción que prevé.

Así que, si la ignorancia de la ley no deja de presentar cierto inconveniente respecto a la exposición a una eventual responsabilidad jurídica, qué decir de la ignorancia de la pena en el entendido de que si bien nadie conoce la ley en su totalidad, menos aun se puede conocer la particularidad de los pagos, es decir, sin que previamente se tenga 
conocimiento de la ley cuya violación produce la acreencia de la sanción. Puedo saber que una acción está prohibida (o puedo haberlo deducido), pero desconozco los pagos asociados a su comisión y, aun más, desconozco la estructura del sistema judicial y las estimaciones que determina el derecho para cada caso particular. Lo que sería imposible es conocer la sanción e ignorar la conducta que prescribe en tanto que la sanción no tiene "vida propia" sino que debe estar atada, en términos de su consecuencia, a una prescripción de conducta formalmente indicada (típica). Indudablemente, en términos cuantitativos, la ignorancia de la pena supondría un problema mucho mayor que el atribuible a su predecesora.

\section{EL PROBLEMA DE LOS PAGOS}

Es pertinente anotar que el individuo, frente al orden y la obligatoriedad que suponen las normas, se expone a un repertorio de sanciones que, aún sin conocer en su particularidad, sabe que existe. Derivando esta proposición hasta la estimación de reglas "desconocidas" (producción legislativa y/o jurisdiccional) como actos que implican cierta amenaza (riesgo), es indudable la presencia de costos sociales difícilmente cuantificables pero ciertamente plausibles. Es decir, cuando la promulgación y la publicidad de la ley, que son los recursos primarios con que el derecho supone resuelto, sistémicamente, el problema de ignorancia, no circulan con el nivel suficiente para legitimar la eficacia del principio.

(...) en condiciones más complejas, comolas que caracterizan a las sociedades contemporáneas, un conjunto de reglas primarias no podrían satisfacer ciertas necesidades, como las de contar con criterios para eliminar la incertidumbre acerca de cuáles sean las normas vigentes, la de modificar el derecho de acuerdo a circunstancias cambiantes o la de contar con decisiones autoritarias y definitivas sobre la aplicación de sanciones (Caracciolo, 1999, p. 68).

En ese entendido, el individuo se encuentra frente a un sistema que se halla facultado para producir y promulgar normas que, sin consultar su voluntad, pueden prohibir algo que asume permitido (o viceversa), y por tanto, en el evento de transgredir una prohibición desapercibida, debe pagar una sanción, aunque, si el sistema opta por no prohibirlo, no tendrá inconveniente alguno, lo cual, dicho sea de paso, no reduce los términos de su vulnerabilidad. Aplicando, tal vez con ligereza, un recurso utilizado por Nozick respecto a prohibiciones e indemnizaciones por daños: "Yo puedo romperte un brazo el próximo mes y si lo hago te daré dos mil dólares como compensación, aunque, si decido no rompértelo no te pagaré nada" (Nozick, 1998, p. 73).

Este ejemplo resulta de un espectador que observa un accidente: un individuo resbala frente a la casa de alguien, se fractura un brazo, y luego de un juicio por daños es resarcido con dos mil dólares. Nuestro espectador asume que el accidente resultó afortunado para la víctima, toda vez que "vale la pena romperse un brazo para obtener dos mil dólares". Estamos seguros que la zozobra producida por la advertencia devendría en un costo de carácter permanente. Así pues, respecto a la validez de la promulgación y la publicidad de la ley como elemento informacional, al igual que ocurre en las familias con niños, el silencio suele ser más preocupante que su algarabía.

Las personas podrían tener una desenfrenada angustia por el ataque, no porque hubieran oído ciertos anuncios particulares, sino porque saben que el sistema permite tales ataques después de los anuncios y, así, se preocupan al no haber oído ninguno. Ellos no pueden ser indemnizados por algo de lo que no han oído y no podrán reclamar indemnización por el miedo que les causaron. Sin embargo, pueden ser víctimas de alguien cuyo anuncio no oyeron (Nozick, 1998, p. 75).

\section{PREDICTIBILIDAD Y CONSISTENCIA}

Si la norma es medida con respecto a su predictibilidad, es claro que la sujeción a ella debe ocupar la instancia de un presupuesto esencial y, 
por ende, no puede estar atada al libre albedrío de las preferencias individuales, como anota la sentencia C-651/97 de la Corte Constitucional: "La obediencia al derecho no puede dejarse a merced de la voluntad de cada uno, pues si así ocurriera, al mínimo de orden que es presupuesto de la convivencia comunitaria, se sustituiría la anarquía que la imposibilita."

Respecto a la ley como factor predictivo, el elemento fundamental que asegura su prevalencia se centra en el sistema de "pagos" a que el individuo se expone por su transgresión, el aparato que garantiza la confiabilidad de las conductas en el colectivo social a tal punto que interesa los terrenos de la responsabilidad jurídica, como dice Werner Krawietz, "sólo podemos ser responsables en forma casuística y, desde el punto de vista jurídico, sólo por una acción imputable" (Krawietz, 2001, p. 35), principio descrito en el Artículo $6^{\circ}$ de la Constitución Nacional.

Digamos, entonces, que una parte fundamental de la pena consiste en el componente de escarmiento que envía una señal al colectivo sobre las implicaciones negativas que produce una violación a la norma. Existe aquí un elemento comunicativo asociado a los sucesos de la vida práctica, un elemento de carácter informacional con origen en la ocurrencia de episodios delictivos y, sobre todo, judicializados, que multipliquen el conocimiento de los pagos. La teoría del observador externo de H. Hart implicaría, en términos de penalización, la necesidad empírica de su registro $y$, por ende, la sociedad estaría en la obligación de proveer al individuo de sus propios referentes, es decir, para que el observador externo pueda de manera efectiva acceder a esa información, el sistema requiere que el delito se produzca para garantizar su vigencia.

Tal observador se satisface simplemente con registrar las regularidades de conducta observables en que parcialmente consiste la conformidad con reglas, y aquellas regularidades adicionales, en la forma de reacción hostil, reprobaciones, o castigos, que enfrentan a las desviaciones. Después de un tiempo el observador externo puede, sobre la base de las regularidades observadas, correlacionar la desviación con la reacción hostil y predecir con un aceptable grado de acierto, calculando las probabilidades, que una desviación de la conducta normal del grupo dará lugar a la reacción hostil o al castigo (Hart, 1992, p. 111).

¿Qué sucede cuando un individuo de 20 años transgrede una ley que durante 25 no se registró en los anales judiciales? Considerando este punto de vista, la desuetud de las leyes debería anclarse a algún tipo de frecuencia mínima que soportara su continuidad, pues es oportuno recordar que según Beccaria "los hombres se regulan por la repetida acción de los males que conocen y no por la de aquellos que ignoran" (Beccaria, 2000, p. 80).

La crítica de Hart a la predictibilidad indica que la violación de una regla no es sólo la base sobre la cual se mide la probabilidad de la reacción hostil en términos de una consecuencia deducible, sino que es la misma transgresión el evento que soporta la necesidad de un mecanismo de censura, la "razón para esa hostilidad".

La objeción fundamental es que la interpretación predictiva oscurece el hecho de que, cuando existen reglas, las desviaciones respecto de ella no son simples fundamentos para la predicción de que sobrevendrán reacciones hostiles o de que un tribunal aplicará sanciones a quienes las transgreden; tales desviaciones son también una razón o justificación para dichas reacciones y sanciones (Hart, 1992, p. 105).

De otra parte, si asumimos el predicado de la "obligación" con referencia a la reacción como mecanismo de aseguramiento de la conducta, estrictamente desde el punto de vista del temor a la sanción, podría pensarse que la sola posibilidad de eludir esta última debilitaría de alguna manera el significado de ese predicado. Un elemento adicional que, de forma instrumental, nos muestra cómo la conciencia de los pagos es un sucedáneo de los términos de justicia. Si tomamos el derecho como un sistema coactivo en estricto sentido, será 
necesario reconocer que el deber no resulta de la concepción de un imperativo moral, ni de la coordinación social, sino de la adecuación a los pagos adversos que produciría su inobservancia.

Si fuera verdad que el enunciado de que una persona tenía una obligación significa que era probable que él sufriera un castigo en caso de desobediencia, sería una contradicción decir que dicha persona tenía una obligación, por ejemplo, la de presentarse a cumplir el servicio militar, pero que debido al hecho de que consiguió huir de la jurisdicción, o pudo sobornar a la policía o al tribunal, no existe la mínima probabilidad de que sea aprehendido o de que se le aplique un castigo (Hart, 1992, p. 111).

Es decir, que no son solo los términos de predictibilidad lo que afecta el argumento en cuestión sino que también lo hace el concepto de responsabilidad jurídica si acogemos la definición que afirma: "persona es aquel sujeto cuyas acciones son susceptibles de imputación" (Werke, citado por Krawietz, 2001, p. 45).

\section{LOS REQUERIMIENTOS DEL SISTEMA}

Existe una racionalidad en el origen de la ley, pero una vez promulgada, la racionalidad cede paso a la autoridad y al orden establecido por ella convirtiéndose para el sujeto en una obligación que no necesita ser comprendida ni asumida por virtuosa sino únicamente acatada. Esta consideración ilustra el hecho de la racionalidad de la ley en referencia a algún orden genealógico que la promueva y la produzca, pero esa racionalidad se pierde en tanto que la promulgación señala el momento en que el discernimiento y la evaluación del individuo con respecto a ella puede construir lo que le sea dable, pero no más allá de la idea. A nadie se le exige estar de acuerdo con ella, sólo es exigible su cumplimiento y sólo se es responsable por su violación.

Que el saber tiene que ver necesariamente con la responsabilidad o, por lo menos, acarrea consigo una responsabilidad del conocedor, puede parecer a muchos cosa comprensible de suyo, aunque no pareciera estar constituida sin más. Ello vale, en todo caso, cuando nos referimos a la responsabilidad jurídica; esto es, a una responsabilidad que se delimita fundándose en el derecho y conforme a sus pautas. El derecho nos puede imponer responsabilidad inclusive cuando nada hayamos sabido o querido, como cuando hemos actuado en forma no pensada, conforme al ejemplo de un delito culposo de tránsito. La ignorancia no exime la pena (Krawietz, 2001, p. 35).

De esta manera, la validez sistémica del derecho se limita a ser evaluada estrictamente en términos de un lenguaje cerrado y estrictamente adecuado a consideraciones fundacionales o constitucionales. Aún bajo la óptica de la asunción de la Carta Política como hipótesis o como ficción, se considera viable una posible circularidad discursiva como la presentada en el principio de ignorancia de la ley, que se considera necesario para el derecho porque el derecho así lo exige, toda vez que el supuesto del individuo informado se aviene a los requerimientos del sistema, es decir, que la ficción jurídica aún bajo la categoría extrasistémica que podría comportar, puede establecerse al interior del sistema mediante disposición legal sin perjuicio de su consistencia lógica. En palabras de Aarnio, aún bajo la égida de una ficción constitucional, si tratamos la validez desde el punto de vista sistémico (interno), "está bien fundado 'cerrar' el sistema de normas mediante una norma supuesta" (Aarnio, 1991, p. 73).

\section{LA SIMPATÍA DE LAS NORMAS}

Respecto a la simpatía es necesario considerar ciertos límites como los establecidos por Sen a los criterios de evaluación: i) Yo deseo X, porque $\mathrm{X}$ es valioso; ii) para mí $\mathrm{X}$ es valioso, porque yo deseo X. Según el autor, "el primer enunciado es inteligible y fuerte en un modo en que el último claramente no lo es. Valorar algo es una buena razón para desearlo, pero desear algo no es una buena razón para valorarlo" (Sen, 1998, p. 67). El problema radica en denotar 
la consistencia de un sistema de creencias y su responsabilidad en la fundamentación del proceso por el que evalúa, en establecer los términos del valor como insumos del juicio, y en tanto que valor, explicar de qué manera circulan, cuidados de la plataforma racionalista de la que dijera Hume: "no es contrario a la razón preferir la destrucción del mundo entero al arañazo de mi dedo" (Hume, 1997, p. 266). Son los ductos de esa información lo que nos interesa, ċen qué términos el individuo se ve precisado a entronizar las informaciones válidas y el mecanismo por el cual rechaza o toma conciencia de las no tan válidas? Dice Wittgenstein que

(...) el niño aprende a creer muchas cosas. Esto es, aprende por ejemplo, a actuar de acuerdo con estas creencias poco a poco, se forma un sistema con las cosas que cree $y$, en tal sistema, algunos elementos se mantienen inmutables $y$ firmes, mientras que otros son más o menos móviles. Lo que se mantiene firme lo hace no porque intrínsecamente sea obvio o convincente, sino porque se sostiene en lo que le rodea (Wittgenstein, 2000, p. 144).

¿Cuál es ese estimador que permite a los individuos actuar en sociedad sin el conocimiento manifiesto de las leyes y aún así vivir sin complicaciones derivadas de ese desconocimiento? Dice Posner que

(...) sería, por ejemplo, extraordinariamente raro que alguien dijera, 'sé y creo que es malo torturar a los niños, pero me gustaría saber por qué es malo'. Uno puede que sea o no sea capaz de darle una razón; pero es muy poco probable que uno pudiera influenciar su creencia (Posner, 1996, p. 12).

Razonamiento que se podría ilustrar con el juego de palabras utilizado por Umberto Eco en un diálogo de Adso de Melk y Guillermo de Baskerville en El Nombre de la Rosa:

(...) ¿Comprendes Adso? Tengo que creer que mi proposición funciona porque así me lo ha mostrado la experiencia, pero para creerlo tendría que suponer la existencia de unas leyes universales de las que, sin embargo, no puedo hablar, porque ya la idea de leyes universales, y de un orden dado de las cosas, entrañaría el sometimiento de Dios a las mismas, pero Dios es algo tan absolutamente libre que, si lo quisiese, con un solo acto de su voluntad podría hacer que el mundo fuese distinto.

- O sea que, si no entiendo mal, hacéis y sabéis por qué hacéis; pero no sabéis por qué sabéis que sabéis lo que hacéis. (Tercer día, Nona)

La convicción moral también supone unos requerimientos básicos de información. Dice Beccaria que la certeza moral no es, en rigor, más que un asunto de probabilidad, "pero probabilidad tal que se llama certeza, porque todo hombre de buen sentido consiente en ello necesariamente por una costumbre nacida de la precisión de obrar, y anterior a toda especulación" (Baccaria, 2000, p. 54). ¿Será por esa precisión de obrar que no es exigible a los turistas apercibirse de los presupuestos legales mínimos de un país que visitan por primera vez, más allá del peligro de un posible decomiso de minifaldas en las aduanas islámicas? O tal vez pueda resultar más dúctil la utilización de la simpatía y la obediencia espontánea de las leyes, en consonancia con la corrección de obrar.

\section{EL DERECHO NATURAL}

El derecho natural, desde Aristóteles, asume lo legal como residuo de una ley que prevalece sobre cualquier evaluación o reconocimiento: "Natural es lo que en todas partes tiene la misma fuerza y no depende de nuestra aprobación o desaprobación... Legal es lo que en un principio es indiferente que sea de este modo o del otro, pero que una vez constituidas las leyes deja de ser indiferente" (Aristóteles, 1992, p. V-8). De otro lado el derecho natural de la patrística no recurre a mayores extensiones respecto al conocimiento de la ley toda vez que afirma (no 
supone) la "participación" de los hombres en la ley divina por medio de la gracia y el libre albedrío agustiniano. Ya con anterioridad a Agustín, entre las epístolas paulinas sobre el conocimiento de la ley podemos destacar:

Cuantos hubiesen pecado sin Ley, sin Ley también perecerán; y los que pecaron en la Ley, por la Ley serán juzgados; porque no son justos ante Dios los que oyen la Ley, sino los cumplidores de la Ley, ésos serán declarados justos. En verdad, cuando los gentiles, guiados por la razón natural, sin Ley, cumplen los preceptos de la Ley, ellos mismos, sin tenerla, son para sí mismos Ley (Romanos, II, 12).

En cuanto al individuo como sujeto de "participación", en Santo Tomás la ley natural "no es otra cosa que la participación de la ley eterna en la criatura racional" (1987, Q. 91, a 2), por lo cual es la que más tiene "razón de ley" debido a que no es esencial su promulgación, la Ley humana será entonces "cierta ordenación de la razón al bien común y promulgada por el que tiene el cuidado de la comunidad" (Tomás de Aquino, 1987, Q. 90 a 4).

Pero la Edad Media demostró que aún en esos términos, una vez empoderado el sistema, los requisitos de su consistencia exigieron que los más sólidos métodos de discernimiento fueran peligrosamente instalados en los terrenos de la herejía. Cualquier proposición ajena al monopolio hermenéutico $y$, por supuesto, político del sistema pontificio, como la ciencia experimental, fue declarada convulsiva. De ahí que la sacralidad no requiriera de tantas explicaciones como de satisfacciones:

(...) he sido juzgado vehementemente como sospechoso de herejía, esto es, de haber creído y sostenido que el Sol es el centro del Universo y que es inmóvil, y que la Tierra no es el centro y que se mueve. Por ello, queriendo apartar de la mente de Vuestras Eminencias y de todo fiel cristiano esta vehemente sospecha, justamente concebida a propósito mío, con sinceridad de corazón y no fingida fe abjuro, maldigo $y$ aborrezco los mencionados errores $y$ herejías, y en general cualquier otro error, herejía o secta contraria a la Santa Iglesia ${ }^{1}$.

Se dice que luego de su abjuración, Galileo farfulló una frase que la leyenda se ha encargado de aclarar: eppur, si muove (y sin embargo se mueve), un juicio en el que cada parte guardaba las claves del universo para señalar su virtud. Una ruptura manifiesta al interior de una misma escala conceptual: un orden natural desplazando a otro.

El método de investigación científiconatural de Galileo, sobre todo, actúa como una sensación en el mundo científico de entonces, incluyendo en éste también la teoría del Derecho natural. Y es que, en efecto, en ningún otro descubrimiento científico aparece tan clara y tangiblemente como en el descubrimiento de la ley de la caída de los cuerpos, por Galileo, la oposición entre la nueva investigación matemático-casual de la naturaleza y la imagen del mundo teleológica e intuitiva de Aristóteles y Santo Tomás (Welzel, 1957, p. 130)

Fue necesario entonces trascender el lenguaje para que el pensamiento lograra la formulación de un nuevo orden, casualmente no en dirección al cielo sino a las estrellas. Pero aún en el orden moderno el sistema requiere de nuevas plataformas de legitimación. La gran variedad de lenguajes presentes en las sociedades indica que el predicamento subsiste en los más variados niveles, como nos refiere Carl Sagan: "En 1993, la autoridad religiosa suprema de Arabia Saudí, el jeque Abdel-AzizlbnBaaz, emitió un edicto, o fatwa, declarando que el mundo es plano. Todo el que crea que es redondo no cree en Dios y debe ser castigado" (Sagan, 1998, p. 351). En términos del problema de la ley y su conocimiento, podemos decir que la ignorancia

1 Fragmento de la abjuración de Galileo Galilei en el Convento de Minerva en 1633. 
del derecho supone una doble vía: de un lado, la de sus gobernados, y del otro, la que puede caber en sus preceptos. Al igual que ocurre con la providencia del juez, el sistema no cuenta con la posibilidad de abstención. Ya se trate de la más confusa proposición o de los casos difíciles, el derecho está obligado a resolver, y con ello a producir elementos de validez, aunque esto último pueda suponer un problema aún más complejo: "El derecho se pronunció sobre la ciencia, ¿en virtud de qué saber? La ciencia decide sobre el derecho. ¿Con qué derecho?" (Serres, 1991, p. 108).

\section{EL CARÁCTER PENAL DEL PRINCIPIO DE IGNORANCIA}

Siendo la sanción el componente coactivo de la ley, el elemento que asegura buena parte de la "positividad" del derecho, consecuentemente el análisis requiere, de una parte, establecer las implicaciones de la sanción en cuanto pago directo sobre la conducta; $y$ de otra, las consideraciones a evaluar por parte del sistema jurídico desde su acepción de "órdenes respaldadas por amenaza". Aquiles Arrieta Gómez utiliza el siguiente ejemplo para recrear el problema de la ignorancia:

Tres jóvenes estudiantes recién graduados del colegio, dos de ellos de 19 años y el otro de 20 , deciden protestar por la decisión del ejército de enviar a zonas de alto riesgo a varios de sus compañeros que están prestan do actualmente servicio militar. Uno de ellos, recordando sus clases de democracia, en las cuales se abogaba por la importancia del derecho a la libertad de expresión, propone hacer una manifestación pública. Otro de ellos, el cual se precia de una gran vena artística, recordando la importancia de la simbología para los movimientos pacifistas, propone que dicha manifestación sea simbólica. Dos semanas más tarde, los tres jóvenes se reúnen en la Plaza de Bolívar disfrazados como momias, con lo cual atraen la atención de un gran número de personas. Uno de ellos comienza a cantar el Himno Nacional, pero alterando la letra, de tal forma que se burla todo el tiempo de lo violentos y sanguinarios que son los colombianos. Otro toma una bandera de Colombia en sus manos la rasga, luego quema los pedazos que le quedan. El último toma un dibujo del escudo de Colombia, primero lo escupe y luego lo tira al suelo y lo pisotea. Al terminar el acto la policía los detiene. Tiempo después se les informa que se les acusa de cometer el delito de "ultraje a emblemas o símbolos patrios" (artículo 117 del Código Penal), según el cual, quien ultraje públicamente la bandera, himno o escudo de Colombia, incurrirá en prisión de seis meses a dos años. Una vez son informados, ellos manifiestan no saber que tal conducta fuera ilegal y alegan ser en extremo respetuosos de la ley. De haber sabido que esto era así, nunca hubieran actuado de tal forma; jamás atentarían en contra de una de las cosas que más quieren y respetan, su patria (Arrieta, 1999, p. 192).

Cuando se analiza el desconocimiento legal de los ciudadanos por sus resultados en cuanto pagos derivados de la conducta, el enfoque parece remitirse a la ignorancia de la pena antes que a la ignorancia de la prescripción, pues ésta última implica el ordenamiento de los comportamientos mientras aquella es el costo que debe sufragar su transgresión. El objetivo de la ley, en el caso descrito no puede ser otro que proteger y dignificar elementos, simbólicos, de la dignidad nacional. ¿Quién ignoraría que su irrespeto supone algún tipo de transgresión? Es más, en la circunstancia queda demostrado que es precisamente la conciencia de la transgresión lo que alienta el perfil de la "protesta", pues existe una voluntad expresa y decidida hacia una acción que los estudiantes, saben, no sólo llamará la atención, sino que lo hará merced a que será censurada. No obstante, es poco factible que abunden opiniones razonables a 
favor de una condena en los términos previstos por aquel código².

Por fortuna, el Código Penal vigente, en su Artículo 461 establece "El que ultraje públicamente la bandera, himno o escudo de Colombia, incurrirá en multa". Es de anotar que la prescripción de la norma ha prevalecido, pero el hecho que nos resulte más grata no tiene otro fundamento que la variación en los pagos. Por tanto, no sería clara la atribución de mayores responsabilidades al principio de ignorancia, en este caso, mientras no se estime previamente la magnitud de la sanción impuesta por la norma desatendida.

En efecto, las normas jurídicas pueden presentar dos fuentes de análisis: de un lado el señalamiento de la conducta a seguir y, de otro, el aseguramiento que supone su coacción, la sanción por su incumplimiento. Al respecto, cabe preguntarse entonces ¿qué tipo de función se establece entre la obligación y la magnitud de los pagos? Hart desvirtúa la idea de tratar los presupuestos de obediencia a la ley en referencia a la predictibilidad o probabilidades de riesgo, renunciando a los enunciados psicológicos que supone el término obligación.

Algunos teóricos, entre ellos Austin, advirtiendo quizá la general irrelevancia de las creencias, temores y motivos de una persona respecto de la cuestión de si ella tenía obligación de hacer algo, han definido esta noción no en términos de esos hechos subjetivos, sino en términos de la probabilidad o riesgo de que la persona que tiene la obligación sufra un castigo o un "mal" a manos de otros en caso de desobediencia (Hart, 1992, p. 104)

Pero una estimación moral frente a la obligación puede tomar múltiples razonamientos, no sólo en cuanto a factores externos sino también en tanto categoría deontológica. A este respecto dice Adam Smith, valiéndose de un ejemplo que, al

2 Decreto 100 de 1980 (Código Penal derogado por la Ley 599 de 2000). parecer, ya en el siglo XVIII peinaba canas: "Por poner un ejemplo trillado: un atracador, mediante amenazas de muerte, obliga a un viajero a que se comprometa a entregarle una determinada suma de dinero. Ha sido muy cuestionado el que una promesa arrancada así por medio de una fuerza injusta deba ser considerada obligatoria" (Smith, 1997, p. 577). Lo que preocupaba a Smith no era si el individuo estaba obligado frente a la amenaza sino si se sentía en el deber de cumplir la palabra empeñada o no, otorgándole al individuo un repertorio de consideraciones que trascienden la esfera de los posibles pagos externos. ¿Acaso el hecho de que el ultraje a símbolos patrios proporcione pagos negativos diferentes al señalado (seis meses a dos años de cárcel vs. una multa) replantearía los términos de la obligación?

Hart parece rescatar el ejemplo respecto a si se está ante la misma obligatoriedad frente a diversos niveles de pago, lo mismo que frente a distintos factores externos que puedan demandar obediencia, como ilustra la diferencia entre estar obligado a algo y verse obligado a ello: el asaltante A ordena a la víctima B la entrega del dinero y amenaza con matarlo si no obedece. Un elemento esencial a tener en cuenta radica en la importancia de los pagos sobre los contenidos de la obligación.

Parece claro que no pensaríamos que $\mathrm{B}$ se vio obligado a entregar el dinero si el daño con que se lo amenazó hubiera sido, de acuerdo con la apreciación común, un daño trivial en comparación con las desventajas o consecuencias serias, para $\mathrm{B}$ o para otros, de acatar las órdenes. Tal sería el caso, por ejemplo, si A simplemente hubiera amenazado a $\mathrm{B}$ con un pellizco (Hart, 1992, p. 103).

De tal suerte, se podría estimar que en términos de "pagos" no se estaría ante el mismo nivel de obligatoriedad frente a una pena de prisión de seis meses a dos años que frente a una sanción pecuniaria, guardando la debida dimensión respecto al monto de esta última. De resultar procedente este argumento, entonces no sólo 
el principio de ignorancia sino la ley en toda su dimensión se circunscribiría al interior de una escala de valores ya no de convivencia, orden y justicia, sino de la prevista en los términos del castigo. Siguiendo la línea del ejemplo de los estudiantes, puede pensarse que lo establecido en el Decreto 1967 de agosto 15 de 1991, en concordancia con el antiguo código, por el cual se reglamenta el uso de los símbolos patrios, tal vez sea desconocido por gran cantidad de colombianos.

Veamos dos artículos que pueden resultar útiles:

Artículo 1. Es obligación izar la Bandera Nacional en todo el territorio colombiano en los edificios, casas y dependencias oficiales y particulares, en las siguientes fechas: 20 de julio, 7 de agosto, 12 de octubre, 11 de noviembre y fiesta nacional del Sagrado Corazón de Jesús. Se izará enlutada y a media asta en los días declarados oficialmente como duelo nacional y en las ocasiones que lo disponga expresamente el Congreso Nacional o el Órgano Ejecutivo.

Artículo 19. Compete a los alcaldes o a quienes hagan sus veces, imponer multas de cinco (5) a diez (10) salarios mínimos diarios legales: i) a quien no ice la Bandera Nacional en lugar visible al público en los días indicados en el presente Decreto; ii) a quien ice la Bandera Nacional en mal estado, desteñidos los colores o alterada la composición de ellos en su forma original, iii) a quien irrespete los Símbolos Patrios.

Alterando deliberadamente los presupuestos del ejemplo de los estudiantes, digamos que un ciudadano de credo anglicano se enfrenta a los pagos del incumplimiento de la norma. Éste quizás no entendería, aun conociendo el texto, los nexos que lo obligan a celebrar una fiesta religiosa de la cual no se siente parte. Pero en esencia, la inconformidad resulta del desconocimiento de una norma por cuyo incumplimiento se le exige el pago de una sanción. Digamos también que este ciudadano es meticuloso en sus gastos y por irrisoria que pueda resultar la sanción, desea evitar su pago a toda costa. Obsérvese que se han atenuado los presupuestos de los pagos en tanto el individuo no se enfrenta a pena de prisión sino a una multa, al tiempo que se incrementan los presupuestos de desconocimiento al establecer que el objetivo y el alcance de la norma son ignorados por completo: el individuo no izó la bandera, pasando por alto la fiesta del Sagrado Corazón de Jesús.

Es válida la presunción de que un país con libertad de cultos no "debe" obligar a sus ciudadanos a participar en forma alguna de celebraciones religiosas ajenas a la suya, y aún podría manifestar su contrariedad frente al principio mediante el cual el ordenamiento jurídico le impide evadir la multa so pretexto de ignorar la ley, aunque en ese desconocimiento radique la causa última de su incumplimiento. Pero tampoco aquí sería de recibo atribuir responsabilidades al principio de ignorancia, por lo menos mientras no se resuelva la evaluación de aquello que la ley prescribe.

\section{LA CONSIDERACIÓN DE EQUIDAD}

El caso es similar en las críticas que desestiman el principio en defensa de algún tipo de desaventajados: iletrados, simples, individuos que no tienen acceso a una estructura que proporcione un espacio de igualdad más que en los términos de responsabilidad frente a la ley y su conocimiento. Así se aprecia en el alegato de la demanda por inconstitucionalidad del artículo 9 del Código Civil, que la Corte Constitucional resuelve mediante sentencia C-651/97, caso cuya sola admisión implica que el tribunal valoró de alguna manera los argumentos en razón de los cuales resultaba violatorio de los presupuestos de igualdad y acceso a la justicia, como también de los principios de presunción de inocencia y buena fe. En los señalados términos reivindicativos arguyen los demandantes:

¿Cómo se puede entender la existencia de este fin del Estado, en un país 
como el nuestro, en donde el acceso al conocimiento de la ley se da por medios restringidos? Con esto queremos decir que aunque existen los medios idóneos, estos son limitados para un grupo de la población, así, no es igual el acceso que tiene un habitante de la capital (con cultura promedio) al que tiene uno de las zonas marginadas de Colombia. Por lo tanto, no se puede juzgar sobre los mismos parámetros a uno y otro, pues estaría alterando el orden social justo $y$, de paso, volveríamos al establecimiento de una responsabilidad objetiva.

Estos argumentos no dejan de presentar alguna limitación frente a los niveles de exclusión y pobreza, pues es necesario observar aquellos elementos de la marginalidad que operan a nivel de síntoma. Por poner un ejemplo, la legislación mexicana en su Código Civil de 1928 otorga al juez la posibilidad de atenuar la responsabilidad del infractor dependiendo de los términos de exclusión que suponga su circunstancia. En su Artículo 21 prescribe:

La ignorancia de las leyes no excusa de su incumplimiento; pero los jueces, teniendo en cuenta el notorio atraso intelectual de algunos individuos, su apartamiento de las vías de comunicación o su miserable situación económica, podrán si está de acuerdo el Ministerio Público, eximirlos de las sanciones en que hubieren incurrido por la falta de cumplimiento de la ley que ignoraban o de ser posible, concederles un plazo para que la cumplan, siempre que no se trate de leyes que afecten directamente el interés público.

En escenarios de justicia donde el individuo puede verse expuesto a vivir en determinadas condiciones de marginalidad, no deja de resultar válido que se le permita en algunos casos recurrir a su escenario de vida como justificación de la transgresión y, con, ello aminorar o librarse de la sanción legal, tal como puede apreciarse en el Artículo 56 del Código Penal colombiano:
El que realice la conducta punible bajo la influencia de profundas situaciones de marginalidad, ignorancia o pobreza extremas, en cuanto hayan influido directamente en la ejecución de la conducta punible y no tengan la entidad suficiente para excluir la responsabilidad, incurrirá en pena no mayor de la mitad del máximo ni menor de la sexta parte del mínimo de la señalada en la respectiva disposición.

Siguiendo el texto de Joaquín Costa (1901) encontramos nuevamente el problema traducido en los mismos términos de denuncia:

Entre las circunstancias de la ley contaban los antiguos doctores la de que había de promulgarse por escrito, fundándose en la definición de ella dada por Aristóteles, Cicerón, San Isidoro, Santo Tomás y otras autoridades; llegando algunos, nuestro Torquemada por ejemplo, a considerar la escritura como de la esencia misma de la ley, y es maravilla no les ocurriese que la promulgación por escrito donde la mayoría no sabe leer, es tan incongruente como lo sería "pregonar las leyes en un pueblo de sordos, o fijar en las esquinas los bandos a que debiera atemperar su conducta una nación de ciegos (Costa, 1901, p. 14).

\section{SIMPATÍA Y LEGITIMIDAD}

Una de las tensiones que presenta el principio de ignorancia se halla, a su vez, en el principio de culpabilidad, más exactamente en aquel elemento que subyace en la conciencia de antijuridicidad que lo diferencia del dolo, pero que en relación a su tratamiento termina por converger en similares estimaciones: "Si se acepta que el "dolo" implica conciencia de antijuridicidad, entonces la ignorancia de la ley penal debería ser excusa en ciertos casos, pues suele suceder que quien desconoce los preceptos legales, en muchas ocasiones, desconoce que su acción es antijurídica"(Arrieta, 1999, p. 193). 
Como bien agrega el autor, el problema es, en parte, que "la mayoría de tipos penales no contemplan dicha forma de culpabilidad, sólo sancionan el dolo". Nótese que la apelación a la diferencia entre los delitos culposos y el dolo puede considerarse una respuesta sana al problema de esta tensión: mientras el dolo supone la consciencia de antijuridicidad, la ignorancia se establece al interior de los dominios inconscientes de la culpa, diferencia que aún en los espacios mismos de la inconsciencia más absoluta puede hacerse evidente ${ }^{3}$.

Pero el hecho que los tipos penales no contemplen rigurosamente esta diferencia en su estructura sancionatoria no es un dilema propio del principio de ignorancia sino de la indeterminación de sus esferas por parte de la misma estructura normativa. Se podría pensar, entonces, en razones que apuntan a la imposibilidad de evaluar el principio de ignorancia per se, en tanto no prescribe conducta alguna $y$, por ende, carece de sanción específica. Aún bajo la categoría de norma, ignorantia legis neminem excusat no posee una instancia propia.

Decir que su texto obliga al conocimiento de la ley no es exacto por cuanto el hecho de ignorarla no implica directamente una transgresión. Tal vez una forma justificable de evaluarlo en su particularidad estaría en el evento de que la ignorancia de la ley se declarara delito o prescribiera una responsabilidad del tipo de la establecida en el Artículo 95 de la Constitución Nacional “(...) Toda persona está obligada a cumplir la Constitución y las leyes". ¿Cómo recrear la "dificultad" del principio sin atender a

3 En un jocoso relato titulado "En el cielo de los Conceptos Jurídicos" de Rudolf Von Ihering, se puede percibir que aún desde la difusa dimensión de un sueño intranquilo, es posible distinguir la diferencia entre la faz taimada del dolus y el aire irreflexivo y despreocupado de la culpa, cuyo rostro es identificado con el de un majadero (Ibáñez, 1995, p. 180). Una caracterización similar puede adecuarse a esa diferencia cuando Dworkin, citando a Holmes, señala que "hasta un perro sabe cuál es la diferencia entre que le den una patada y que tropiecen con él" (Dworkin, 1984, p. 56). los antecedentes sobre los que se estima, es decir, sin vicios aparentes, ya sea en la prescripción de la norma, en la pena que implica o aún en la sentencia que interpreta y decide?

De lo contrario, cabría suponer que el sistema jurídico está en capacidad de producir normas ya no controversiales sino insólitas. Pero aún así, la dificultad no estribaría en la restricción legal para excusarse en su desconocimiento. Por tanto, en términos analíticos, el principio conlleva un instrumento específico de valoración: indica hasta qué punto una norma es observada sin necesidad de atender a su prescripción ni a la pena que impone. Básicamente se trataría de un estimador capaz de satisfacer dos predicamentos respecto a la asunción de la ley: i) la ley como aquel precepto que todos deben conocer; ii) aquel orden que el precepto debe atender y respetar para convertirse en ley.

Tal vez ese abismo que parece dividir fatalmente y para siempre al legislado de la ley no sea real, sino obra de nuestra fantasía creadora, puesta al servicio de nuestra pereza intelectual; tal vez nuestra fatalidad no esté en la naturaleza de las cosas, sino en el modo cómo los hombres las hemos visto e interpretado: acaso el problema no fue bien planteado en sus orígenes, y en vez de decir que «el pueblo está obligado a conocer y cumplir todas las leyes», deban invertirse los términos diciendo que «no son verdaderamente leyes sino aquellas que el pueblo conoce... y refrenda cumpliéndolas, traduciéndolas en sus hechos (Costa, 1901, p. 17).

Indudablemente, buenas leyes serían aquellas que los hombres cumplen aún desconociendo su texto (leyes simpáticas). De ahí, que el principio de ignorancia pueda no sólo estimar el vínculo entre la información y la norma, sino también la justeza de sus prescripciones y pagos. Respecto a la posibilidad de leyes insólitas en el derecho o atribuibles a nuestra fantasía creadora, el aceptar la pertinencia del concepto de "buenas leyes" implica la existencia de otras que pueden no serlo, 
y ningún término más adecuado para definir esta última categoría que el de leyes artificiales.

Tal vez, en comparación con las leyes naturales, las normas del sistema jurídico puedan suponer cierta artificialidad, aún sin que sugiera algún tipo de menoscabo sobre sus bondades. Dice Hume que estas leyes aunque necesarias "son enteramente artificiales y de invención humana y que, por consecuencia, la justicia es una virtud artificial y no natural" (Hume, 1997, p. 339), entendiéndose por artificial el objetivo de su diseño en aras del "bien común". Posiblemente, donde la naturaleza, más que una posible solución, se presenta como un aspecto adicional a determinar; el argumento de Spinoza según el cual el problema dependería menos de la circunstancia y más de la naturaleza humana puede resultar más propicio al dilema de la ignorancia:

No todos, en efecto, están naturalmente determinados a obrar según las reglas y las leyes de la razón, sino que, por el contrario, todos nacen ignorantes de todas las cosas $y$, antes de que puedan conocer la verdadera norma de vida y adquirir el hábito de la virtud, transcurre gran parte de su vida, aun en el caso de que reciban una buena educación. Entretanto, sin embargo, tienen que vivir y conservarse en cuanto puedan, es decir, según les impulse el apetito, ya que es lo único que les dio naturaleza, que les negó el poder actual de vivir según la sana razón. No están, pues, más obligados a vivir según las leyes de la mente sana, que lo está el gato a vivir según las leyes de la naturaleza del león (Spinoza, 1988, XVI, 20).

Un sistema de derecho natural supone la universalidad $e$ inmutabilidad de las leyes, a tal punto que no habría espacio a la ignorancia en el entendido de que la ley permea toda estructura de conciencia y racionalidad. Pero la historia demuestra que al abrigo de este sistema han prosperado las más diversas y contradictorias doctrinas, incluyendo al estado moderno que aún erigiéndose sobre sus pilares no puede pensarse por fuera de la dimensión de un régimen; y en ese entendido, si bien la justicia puede ser descrita en términos del diseño institucional, la evaluación de su moralidad sugiere un espacio abierto a la naturaleza humana, máxime si se atiende a la formulación de Smith según la cual "todo sistema de derecho positivo puede ser considerado como un intento más o menos imperfecto de un sistema de jurisprudencia natural o de una enumeración de las normas concretas de la justicia” (Smith, 1997, p. 592).

Obviamente, por fuera de estos espacios de estimación, la existencia de las normas jurídicas toma verdadera relevancia en tanto que, por un lado, opera en términos de regulaciones que pueden escapar al conocimiento, aceptabilidad y discernimiento del sujeto, lo cual supondría algún tipo de antipatía; y, por el otro, constituye un espacio de amenaza capaz de generar pagos negativos directos. Pero aún en esta circunstancia sería temerario deducir la impertinencia de las leyes como el producto de su "artificialidad", entendiendo por esto último el diseño y la reflexión humana, dada la difusa línea que divide las leyes naturales de las que pueden ser consideradas artificiales: "aunque las reglas de la justicia sean artificiales no son arbitrarias. No es una expresión impropia llamarlas leyes de la naturaleza, si por natural entendemos lo que es común a una especie o aun si designamos por ello lo que es inseparable de las especies" (Hume, 1997, p. 312). De ahí que el análisis se derive a espacios donde la existencia de normas simpáticas pueda, suprimiendo la posibilidad de leyes artificiales, derivarse a la formulación de un orden espontáneo.

El juicio sobre la corrección de una ley, la simpatía moral, supone un nexo entre los individuos en torno a aquellos elementos que lo identifican con el otro y, con ello, el predicado de la corrección moral instala al hombre en escenarios de consenso. En ese entendido, una diferencia plausible entre un sistema de derecho natural y los escenarios de la valoración moral consiste en que aquel puede operar en términos de la evaluación individual, v. g. Antígona no requirió de aplauso o aceptabilidad 
algunos para contravenir la prohibición del rey y sepultar el cadáver de su hermano.

No obstante, ambas estructuras, el derecho natural y la moral, se erigen en bastiones a superar por parte de la positividad del sistema jurídico. Pero ¿cuál sería esa categoría capaz de procurar elementos de juicio unívocos que demuestren alguna supremacía sobre las demás fuentes de evaluación moral? Tal vez, la discusión sobre los criterios con que se establece una plataforma de evaluación moral deba, previamente, esclarecer los determinantes últimos de la corrección de una conducta. Hart establece ciertas diferencias cronológicas respecto al carácter de las normas en tanto ordenamientos jurídicos independientes de las prescripciones morales:

Posiblemente podría encontrarse alguna forma embrionaria de esta distinción si hubiera algunas reglas mantenidas primariamente mediante amenazas de castigo para el caso de desobediencia, y otras mediante la apelación a un presunto irrespeto a las reglas o a sentimientos de culpa o de remordimiento. Cuando se supera esta etapa primitiva, y se da el paso desde el mundo prejurídico al mundo jurídico, de modo que los medios de control social comprenden ahora un sistema que contiene reglas de reconocimiento, de adjudicación y de cambio, la distinción entre las reglas jurídicas y las otras se convierte en algo definido (Hart, 1992, p. 210).

Atendiendo a esta consideración, es precisamente en los escenarios del "mundo jurídico" donde surge el problema de su ignorancia, es decir, que el predicamento del conocimiento de la ley se verifica en términos de la positividad del derecho y, al interior de esa positividad, específicamente en lo que respecta a la coerción. Cuando Hart afirma que es pertinente atender a ciertas consideraciones antes de asumir el derecho como la simple obligatoriedad frente a la coacción, se vale para ello de un nexo de responsabilidad frente al conocimiento de la ley por parte de sus gobernados: Cuando un asaltante da una orden respaldada por amenaza, "Entrégueme esos billetes", el elemento informativo que garantiza la obediencia es completo y suficiente por cuanto la víctima es receptora directa de esa expresión, caso que ilustra los problemas de la promulgación en términos de su cobertura. El hecho de que la orden sea dirigida a éste último y no a un cuerpo abstracto, como supondría el que el asaltante expresara ese deseo en un cuarto vacío, es lo que diferencia el acto de dictar normas y la orden dada a otros de hacer o abstenerse de algo.

Puede ciertamente ser deseable que las normas jurídicas sean puestas en conocimiento de aquellos a quienes se aplican, inmediatamente después de ser dictadas. El propósito del legislador al crear normas se frustraría si no se procediera así en la generalidad de los casos, y los sistemas jurídicos disponen comúnmente, mediante reglas especiales sobre promulgación, que tal cosa se lleve a cabo. Pero las normas jurídicas pueden ser completas en cuanto tales antes de ser publicadas y aunque no se las publique. En ausencia de reglas especiales en contrario, las reglas jurídicas son válidamente creadas aún cuando las personas afectadas por las mismas tengan que averiguar por su cuenta qué normas han sido dictadas y quiénes son los afectados por ellas (Hart, 1992, p. 28)

Imaginemos un espacio de solución al problema del conocimiento de la ley: haciendo abstracción, prescindir del principio de ignorancia llevaría implícita cierta negación de la posibilidad de leyes antipáticas en el ordenamiento jurídico y, con ello, a una suerte de imposibilidad discursiva si se atiende a la naturaleza conflictiva de la sociedad y a la inconmensurable diversidad de intereses verificados en ella, a menos que se interesen terrenos próximos a los escenarios de aceptabilidad que supondría la dictadura. ¿Pero es acaso argumento para sugerir que el espacio que supone dificultad para el principio de ignorancia sea un área tan independiente como para promover leyes insólitas o de tipo 
dictatorial? ${ }^{4}$ Para Smith, es necesario establecer la fuente de esa evaluación sobre la corrección de nuestras acciones:

La decisión sobre esta cuestión, que quizá no pueda establecerse con mucha precisión, dependerá de dos circunstancias distintas; primera, de lo naturalmente agradable o desagradable del sentimiento o afecto que nos impulsaría a una acción independientemente de cualquier consideración a reglas de carácter general; $y$ segundo, de la precisión y exactitud, o de la imprecisión e inexactitud de las reglas mismas (Smith, 1997, p. 312)

\section{EL PROBLEMA MORAL}

El punto esencial del análisis se centra en la definición de los objetivos finales del derecho penal. Cuando se habla de pagos negativos como mecanismo de reducción de alguna actividad, Hart trae a colación los casos en que los impuestos y las multas pueden realizar esos mismos objetivos, con la diferencia fundamental de que mientras la ley se orienta a la dirección de las conductas del individuo ordinario ejerciendo la presión implícita de la sanción sobre aquellas acciones consideradas delictivas, el caso de las multas y los impuestos no conllevan el hecho de que deban desaparecer, en el sentido de que al estado no requiere que tales actividades sean abandonadas. Pero de otra parte, establece serias consideraciones sobre el componente informacional de la sanción:

(...) al reformular el derecho en la forma de una directiva para aplicar sanciones, se gana en claridad, puesto que esta forma

4 Habíamos visto cómo el aparato jurídico, en tanto sistema, requiere de una consistencia que impide la enunciación de ese tipo de leyes, lo que se extiende a los recursos que él mismo ofrece en caso de que se presenten, cual sería la declaratoria de su improcedencia mediante control constitucional. Eso sin perjuicio de las estimaciones que pueda generar el mismo principio de ignorancia sobre la evaluación de la prescripción legal o de la sanción que prevea. pone de manifiesto todo lo que el 'mal hombre' necesita saber acerca de aquél. Esto puede ser cierto, pero parece una defensa inadecuada para la teoría. ¿Por qué el derecho no habría de preocuparse igual, si no más, del 'hombre desconcertado' o del 'hombre ignorante' que está dispuesto a hacer lo que corresponde, con tal que se le diga en qué consiste? ¿O del 'hombre que quiere arreglar sus asuntos', con tal que se le diga cómo hacerlo? (Hart, 1992, p. 50).

De otro lado, si se toman las funciones del derecho penal como mecanismo de aseguramiento de alguna política pública, sea por vía de la vindicta de la ley; o sea en términos de prevención: impedir nuevos daños y lanzar la señal para disuadir a potenciales infractores, bien vale la pena estimar esos recursos de eficiencia y sus nexos con alguna estructura de valores que involucre, en rigor, la formulación moral a la que obedece.

Respecto a estos ámbitos de maximización ${ }^{5}$, Dworkin asume, por ejemplo, que no es clara la razón por la que un juez, convencido de que el remplazo de una norma por otra más eficiente, aunque procure prosperidad a algún sector capaz de derivar sus beneficios al resto de la sociedad, deba convertirse en razón suficiente para hacerlo:

No podemos responder a esta clase de preguntas mediante un análisis que relacione simplemente los medios con los fines. Así pues, las diversas ramas del enfoque profesional de la jurisprudencia fracasaron por la misma razón básica: ignoraron el hecho crucial de que los problemas de jurisprudencia son, en lo más profundo, principios morales, no de hechos legales ni de estrategia. Pero, si la jurisprudencia ha de tener éxito, debe

5 Richard Posner, en su artículo "Utilitarismo, Economía y Teoría del Derecho" [1979] defiende una plataforma ética basada en la maximización de la riqueza. Ronald Dworkin, en respuesta, controvierte ese mecanismo de evaluación con una serie de consideraciones que bien pueden ser deducidas a partir del título de su artículo “¿Es la riqueza un valor?” [1980]. 
poner al descubierto estos problemas y encararlos como problemas de la teoría moral (Dworkin,1984, p. 51).

Volviendo a la línea de Hart, en escenarios en que el derecho puede ser asimilado como ordenes coercitivas, sea que vengan de un asaltante o de un policía que ordena a un conductor detenerse, no es plausible suponer mayores responsabilidades del estado sobre los mecanismos de información legal.

Pero estas situaciones simples no son, y no podrían ser, la forma típica en que funciona el derecho, aunque más no sea que por la razón de que ninguna sociedad podría mantener el número necesario de órganos para asegurar que cada uno de sus miembros sea informado, en forma oficial y separada, de cada uno de los actos que debe realizar. [...] De aquí que la forma típica, incluso de una ley penal (que de todas las variedades de normas jurídicas es la que más se asemeja a una orden respaldada por amenazas), es general de dos maneras; indica un tipo general de conducta y se aplica a una clase general de personas de quienes se espera que adviertan que rige para ellas y que cumplan con lo prescrito (Hart, 1992, p. 26).

Una categoría del derecho bastante próxima al problema de ignorancia, en el sentido que puede mitigar la sanción, se halla en las eximentes mentales. La diferencia se presenta en el hecho de que si bien en ninguno de los casos se halla presente el elemento de voluntad y conciencia, en el caso de la enfermedad mental el sujeto es considerado incapaz de obrar de conformidad, mientras en la ignorancia esa "incapacidad" es plenamente descartada.

Según Dworkin (1984, p. 54 y ss.), algunos críticos desestiman este relajamiento con el argumento de que tales enunciados serían válidos siempre y cuando los objetivos del derecho penal estuvieran en la represalia puesto que no cabe obtener satisfacción alguna al vengarse de alguien que actuó por equivocación o era deficiente mental pero agregan que en tanto se evalúan los instrumentos del derecho en términos de "impedir que el delincuente haga más daño y disuadir mediante su ejemplo a otros", tales prerrogativas resultarían contraproducentes. En palabras del mismo autor, Hart afirma que:

Si se revocaran las eximentes mentales, todos tendríamos que convivir con el hecho de que algún accidente o inadvertencia podría enviarnos a la cárcel o complicarnos en un proceso largo, caro y degradante. En virtud de las eximentes y atenuantes, podemos contar con el hecho de que, en general, sólo seremos procesados por actos ejecutados con plena conciencia de que podrían dar lugar a acusación, lo que ofrece el beneficio accesorio de que quienes sean castigados han tenido por lo menos la oportunidad de tomar y llevar a la práctica una decisión de infringir la ley (Hart, 1992, p. 26).

En términos de su resultado, estos elementos apuntan a la misma dirección: impedir que un hombre sea castigado por un hecho que estaba fuera de su alcance, a saber, la carencia de elementos de voluntad y consciencia que amerita la revisión del castigo otorgado a su comisión en situaciones normales. Este aspecto bien puede ilustrar la diferencia que para ambos casos sugiere el principio según el cual "nadie está obligado a lo imposible". Dworkin concede razón a las opiniones que apuntan a que leyes y sentencias no deben buscar el castigo aún cuando pudieran con él reducir el crimen. Una de ellas, la de Jeromne Hall, un experto penalista, afirma que "el sentido de la eximente basada en enfermedad mental es asegurar que la ley castigue como criminales sólo a los hombres que son moralmente censurables de acuerdo con los estándares convencionales" (Dworkin, 1984, p. 55).

Hart refuta esta tesis con un argumento que apunta a restringir las consideraciones morales respecto a los objetivos jurídicos, a saber, muchos delitos en sí mismos no son moralmente censurables; lo 
cual demostraría, de una parte, que los objetivos del derecho no se reducen a condenar únicamente actos moralmente censurables y, de otra, que no es el objetivo señalado por la moral la razón jurídica de este tipo de relajamientos. Pero Dworkin atribuye a Hart la confusión de dos factores por los cuales la transgresión de una norma puede revestir un mal moral. El primero es que podría ser malo porque el acto que prohíbe la ley es en sí mismo malo; y el segundo, que también podría ser reprobable, ya no por ser en sí mismo malo, sino simplemente por que la ley lo prohíbe; aunque agrega Dworkin: "de esto no se sigue que un hombre sea moralmente censurable toda vez que hace algo que la ley prohíbe. Puede que no sea censurable porque la ley es tan injusta que la obligación moral normal de obedecerla deja de existir" (1984: loc. cit.), dando lugar a la evaluación de órdenes injustas como mecanismo que faculta al individuo para transgredirlas sin perjuicio de repercusiones morales negativas.

En el mismo enfrentamiento de posiciones tan disímiles, es posible apreciar cierta indeterminación en cuanto a los escenarios del derecho y la moral se refiere. No obstante, cuando se estima la tesis del observador externo de Hart se observa una particular característica que consiste en que mientras el sujeto se informa de las conductas de los demás, deja de lado la evaluación propia sobre la acción. En este planteamiento, el observador se muestra bastante afín a la dimensión de un individuo amoral, situado en un punto tal que sus estimaciones se derivan de la misma asunción de las normas como enunciados soportados por los pagos negativos de la sanción: las órdenes respaldadas por amenaza cuya obediencia procede de un tipo de razonamiento particular: "Me vi obligado a hacerlo" (Hart, 1992, p. 112); el mismo razonamiento inapelable que se registra frente a situaciones de indefensión.

En ningún momento, desde el punto de vista externo, se considera el "estar obligado a ello". No parecería prudente, entonces, asumir la sanción como factor a estimar en términos de la corrección de obrar; sino, por el contrario, todo apunta a que los términos de justicia como los de la valentía requieren indefectiblemente de algún tipo de desconocimiento sobre los pagos. Condición que parece no tener cabida más que en escenarios como el derecho natural y la moral, dos grandes escenarios en que pueden operar los presupuestos de la Regla Cero, con la diferencia de que los elemento de simpatía y consenso requeridos por el juicio moral superan la dimensión del derecho natural en tanto la moral garantiza los presupuestos de la simpatía, remontándose sobre los estatutos soberanizados del individuo: "los que reducen el sentir moral a instintos originales del espíritu humano pueden defender la causa de la virtud con la autoridad suficiente; pero carecen de la ventaja que poseen los que explican este sentido mediante una simpatía extensa con el género humano" (Hume, 1997, p. 396).

\section{CONCLUSIONES}

El derecho natural de la patrística sorteaba el problema de la ignorancia a partir del concepto de la "participación" toda vez que por medio de la gracia el sujeto era consciente de los designios de la ley, participaba de ella y en ella. Para el derecho positivo la unanimidad está garantizada, en últimas, por la coerción y el castigo. En términos de la coherencia del sistema jurídico, existen modelos cuyos requerimientos "internos" suponen unos elementos de "cierre" y cuyas estructuras no pueden ser explicadas por fuera de su propio lenguaje. Un ejemplo de ello es evidente en escenarios como el orden matemático, en el cual la explicación de un número específico, digamos el cinco, no es posible sin la intervención de otros números diferentes a él, vale decir, explicar una cifra particular sin intervención de las demás es hasta hoy una empresa imposible, lo cual lleva a la consideración de las matemáticas como una de las más elevadas abstracciones toda vez que en estos términos ningún número es explicable por fuera de su propio lenguaje, de igual forma que una norma jurídica obtiene siempre su validez de otra norma jurídica (Aarnio, 1991, p. 72).

El sistema jurídico, a este respecto, será cabalmente conciso en tanto los términos de valoración de 
una norma y la información a utilizar dependan de las demás. Todo sistema conspira hacia su autovalidación; y más allá, las posibles evaluaciones por fuera del sistema jurídico se hallan a su vez iluminadas por el mismo lenguaje, los requerimientos de la vida en comunidad. Dice Dworkin que la violación de una norma podría implicar un mal moral aunque la conducta condenada no fuera mala en sí misma, sino que es moralmente reprobable precisamente porque la ley lo prohíbe (Dworkin, 1984, p. 54).

A la luz del derecho, se podría plantear una comparación entre la simpatía de la opinión pública respecto a una ley como prueba de su corrección jurídica o todo lo contrario: es la asunción de la norma como vector de ajuste social lo que produce algún grado de certeza en la probidad de los comportamientos: "¿No llevan el patrón y los criterios de existencia de normas válidas o de reglas de recta conducta al resultado del acomodamiento secundario, en el camino de la generalización y abstracción aquí correspondientes, de la conciencia moral y jurídica a la opinión pública y privada, con la consecuencia de que pueda resultar una generalización conceptual adecuada para la solución de problemas y para las decisiones jurídicas?" (Krawietz, 2001, p. 29).

¿La corrección jurídica está en función de la simpatía general o es precisamente la simpatía general la que se construye en función de los términos que el sistema jurídico otorga para su evaluación? Es precisamente a este respecto que se evidencia en Sen el predicamento de una moral colectiva: "Es bastante obvio que la posibilidad de utilizar los principios morales depende de la disponibilidad de la información. Lo que es menos obvio quizás es que la posibilidad de usar la información también depende de los principios morales particulares que se adopten" (Sen, 1998, p. 46).

Debemos señalar que el concepto de corrección implica la existencia de una técnica que supone no sólo mayor conocimiento sino también un lenguaje articulado que no es compartido por la totalidad de la comunidad. Para tal efecto, se establece la dicotomía de la "comunidad Jurídica" entre agentes jurídicos (comunidad real) y legos (comunidad ideal). La primera es concreta porque sólo existe en la práctica jurídica de los entendidos, la segunda es ideal porque "se compone de todos aquellos que se comprometen con las reglas y los principios de la racionalidad" (Aarnio, 1995, p. 62).

Lo interesante de esta comunidad ideal, entendida como audiencia universal exclusivamente en cuanto concierne a la racionalidad del discurso, es que, a diferencia de la real, los legos son los llamados no solo a evaluar sino también a criticar el razonamiento, toda vez que "la idea de un razonamiento jurídico racional presupone que todos tienen a su disposición todas las fuentes materiales. Todos los participantes pueden utilizar la información sin ninguna limitante específica" (Aarnio, 1995); lo que, de cierta manera, revalúa los términos del desconocimiento práctico en tanto pondera la universalidad del discurso racional. ¿Existe, entonces, un requerimiento de espacios por fuera del sistema, espacios de no-derecho como instancia de alguna hipotética evaluación? La causa de Galileo no tiene asidero en el sistema que le enjuicia, si el juez pertenece al sistema ¿cómo esperar que su fallo no se ajuste a los cánones del derecho?

El espacio del derecho incluye las cosas que equivalen a causas o las causas que equivalen a cosas, mientras que el espacio de no-derecho contiene cosas que no son causas, que no lo son aún o que incluso no lo serán jamás. [...] Galileo tiene necesidad de un tribunal cualquiera para que su teoría, probable, se vea canonizada, para que su realidad devenga racional y para que su texto advenga a la verdad (Serres, 1991, p. 138).

De igual forma, si acogemos el razonamiento de la simpatía de una norma como criterio de evaluación externo al sistema, asumiendo esa simpatía como un valor, bien podríamos esperar que una norma se tomara por valiosa en tanto 
redujera los costos de su discernimiento y su observancia o bien, por poner un ejemplo, se ajustara a la ética de la maximización de la riqueza como criterio operativo del análisis económico del derecho. No obstante, cualquier opción que tome debe culminar en su acatamiento, el enunciado anterior sirve a nuestros propósitos en cuanto se aproxima a la estructura que se pretende consolidar, a saber, que una norma antipática difícilmente podría dirigir el comportamiento si no se le conoce de antemano.

En lo que respecta a la consideración de equidad y sin menoscabo de los requerimientos de una justicia social sustantiva, el relajamiento del principio de ignorancia en función de la circunstancia de exclusión supone cierta contradicción técnica. Más aún, tal afirmación pondría de manifiesto que entre los no excluidos los reparos al principio supondrían alguna alteración, lo cual a toda luz resulta poco probable: un ejecutivo de una empresa petrolera realiza una llamada por teléfono celular desde un avión en vuelo para avisar a su familia que está por tocar tierra, ignorando que el ordenamiento jurídico castiga con prisión a quien utilice un teléfono móvil durante el vuelo, puesto que, se estima, pone en serio peligro la seguridad de la aeronave (pese a estudios de institutos de reconocida trayectoria tecnológica que afirman no hallar evidencia que permita asegurar el peligro que supone). ¿Cómo exigirle a un experto en petróleos que sea capaz de deducir el impacto que su llamada tendrá sobre los circuitos de telecomunicación cuando ni siquiera los entendidos se han puesto de acuerdo sobre el particular? Tal vez, el fenómeno de la división social del trabajo pueda hallarse en condición de ofrecer algunas luces al respecto.

A la vez que el desarrollo de nuestro conocimiento de la naturaleza descubre constantemente nuevos reinos de ignorancia, la creciente complejidad de la civilización que tal conocimiento permite construir entraña nuevos obstáculos para la comprensión intelectual del mundo que nos rodea. Cuanto mayor es el conocimiento que los hombres poseen, menor es la parte del mismo que la mente humana puede absorber. Cuanto más civilizados somos, más ignorancia acusamos de las realidades en que se basa el funcionamiento de la civilización. La misma división del conocimiento aumenta la necesaria ignorancia del individuo sobre la mayor parte de tal conocimiento (Hayek, 1996, p. 45)

De lo que se parte para controvertir los argumentos tradicionales con que se objeta o defiende el principio de ignorancia es de la simplificación que supone, así presentar la discrecionalidad de las sanciones legales en términos de algún tipo de justicia social capaz de equilibrar los alcances de la ley respecto a los factores de exclusión (argumento que no sólo presenta cierto eufemismo frente al origen y la magnitud del problema, sino que resulta en cierta contradicción lógica); como soportarlo en la autopoiésis del sistema según la cual, en concordancia con Santo Tomás, la esencia de la ley y el recurso informativo que posibilita su conocimiento estriban en el acto de su promulgación. Todo parece indicar que el conocimiento de la ley supone un problema, cuando menos, más complejo que el usualmente descrito.

\section{REFERENCIAS}

Aarnio, A (1991). Lo Racional como Razonable. Madrid: Centro de Estudios Constitucionales.

Aarnio, A. (1995). Derecho, racionalidad y comunicación social. México: Biblioteca de Ética, Filosofía del Derecho y Política.

Aquino, T. d. (1987). Suma Teológica. Madrid: Austral.

Aristóteles (1992). Ética. México: Porrúa.

Arrieta, A.(1999). La ignorancia de la ley, entre el orden y la justicia. Bogotá: Siglo del Hombre.

Beccaria, C. (2000). De los delitos y de las penas. Madrid: Alianza.

Caracciolo, R. (1999). La noción de sistema en la teoría del derecho. México: Biblioteca de Ética. 
Costa, J. (1901). El problema de la ignorancia del derecho y sus relaciones: el status individual, el referéndum y la costumbre. Consultado el 20 de agosto de 2011 en: http:// www.cervantesvirtual.com/servlet/SirveObras

Dworkin, R. (1984). Los Derechos en serio. Barcelona: Ariel

Hart, H. (1992). El concepto de derecho. Buenos Aires: Abeledo-Perrot.

Hayek, F. (1996). Los Fundamentos de la Libertad. Barcelona: Unión.

Hume, D. (1997). Tratado de la Naturaleza Humana. México: Porrúa

Ibáñez, G. (1995). La Picaresca Jurídica Universal. Bogotá: Ediciones Jurídicas Gustavo Ibáñez.

Krawietz, W. (2001). El concepto sociológico del derecho. México: Biblioteca de Ética.

Nozick, R. (1998). Anarquía, Estado y utopía. México: Fondo de Cultura Económica.
Posner, R. (1996). Maximización de la Riqueza y TortLaw, una Investigación Filosófica. Consultado el 13 de abril de 2011. En http://www.eumed.net/cursecon/ textos/posner-tort.pdf.

Sagan, C. (1998). El Mundo y sus Demonios. Bogotá: Planeta.

Sen, A. (1998). Bienestar, Justicia y Mercado. Barcelona: Paidós.

Serres, M. (1991). El Contrato Natural. Valencia: Pretextos.

Smith, A. (1997). La Teoría de los Sentimientos Morales. Madrid: Alianza.

Spinoza, B. d. (1988). Tratado teológico-político. Madrid, Alianza.

Welzel, H. (1957). Derecho Natural y Justicia Material. Madrid: Aguilar.

Wittgenstein, L. (2000). Sobre la Certeza. Barcelona: Gedisa. 